\title{
3,4-Methylenedioxymethamphetamine (Ecstasy) Inhibits Dyskinesia Expression and Normalizes Motor Activity in 1-Methyl-4-Phenyl-1,2,3,6-Tetrahydropyridine-Treated Primates
}

\author{
Mahmoud M. Iravani, Michael J. Jackson, Mikko Kuoppamäki, Lance A. Smith, and Peter Jenner \\ Neurodegenerative Disease Research Centre, Guy's, King's, and St. Thomas' School of Biomedical Sciences, King's College, London SE1 1UL, \\ United Kingdom
}

Ecstasy [3,4-methylenedioxymethamphetamine (MDMA)] was shown to prolong the action of L-3,4-dihydroxyphenylalanine (L-DOPA) while suppressing dyskinesia in a single patient with Parkinson's disease (PD). The clinical basis of this effect of MDMA is unknown but may relate to its actions on either dopaminergic or serotoninergic systems in brain.

In normal, drug-naive common marmosets, MDMA administration suppressed motor activity and exploratory behavior. In 1-methyl4-phenyl-1,2,3,6-tetrahydropyridine (MPTP)-treated, L-DOPA-primed common marmosets, MDMA transiently relieved motor disability but over a period of $60 \mathrm{~min}$ worsened motor symptoms. When given in conjunction with L-DOPA, however, MDMA markedly decreased dyskinesia by reducing chorea and to a lesser extent dystonia and decreased locomotor activity to the level observed in normal animals. MDMA similarly alleviated dyskinesia induced by the selective dopamine D2/3 agonist pramipexole. The actions of MDMA appeared to be mediated through 5-HT mechanisms because its effects were fully blocked by the selective serotonin reuptake inhibitor fluvoxamine. Furthermore, the effect of MDMA on L-DOPA-induced motor activity and dyskinesia was partially inhibited by 5-HT1a/b antagonists. The ability of MDMA to inhibit dyskinesia results from its broad spectrum of action on 5-HT systems. Serotoninergic receptors appear to play an important modulatory role in L-DOPA-induced dyskinesia, and this study may provide a framework for the use of serotoninergic agents in the treatment of L-DOPA-induced dyskinesia.

Key words: common marmosets; MPTP; dyskinesia; L-DOPA; 3,4-methylenedioxymethamphetamine; MDMA; ecstasy; Parkinson's disease; dopamine; serotonin

\section{Introduction}

Recently, an anecdotal report in an individual with young onset Parkinson's disease (PD) who was receiving L-3,4dihydroxyphenylalanine (L-DOPA) treatment suggested that the recreational use of ecstasy [3,4-methylenedioxymethamphetamine (MDMA)] caused a remarkable improvement in motor disability and dyskinesia severity. Whether the effect observed in a single patient is reflective of the response of other individuals is unknown, as is the mechanism through which MDMA might exert its beneficial actions. Elevation of extracellular 5-HT mediated by MDMA underlies its pharmacological effects and activates various 5 -HT receptors in the brain (Bankson and Cunningham, 2001). On the basis of their distribution, localization, and function in basal ganglia, 5-HT1a, 5-HT1b/d, and 5-HT2a, 5-HT2c receptors may be linked with modulation of the nigro-

Received May 14, 2003; revised Aug. 20, 2003; accepted Aug. 20, 2003.

This work was supported in part by the Parkinson's Disease Society, UK, and The Wellcome Trust. We are grateful to Dr. John Stephenson (Institute of Psychiatry London) for his help during the course of this investigation.

Correspondence should be addressed to Peter Jenner, Neurodegenerative Disease Research Centre, Guy's, King's, and St. Thomas' School of Biomedical Sciences, King's College, London SE1 1UL, UK. E-mail: div.pharm@kcl.ac.uk. Copyright $\odot 2003$ Society for Neuroscience $0270-6474 / 03 / 239107-09 \$ 15.00 / 0$ striatal pathway (Barnes and Sharp, 1999). Only low levels of 5-HT1a receptors are in the striatum (Barnes and Sharp, 1999), but their distribution and density are subject to adaptive changes, because there is a marked upregulation in the striatum of chronically 1-methyl-4-phenyl-1,2,3,6-tetrahydropyridine (MPTP)treated monkeys (Frechilla et al., 2001). 5-HT1a receptors are involved in the control of motor behavior because 5-HT1a agonists such as sarizotan and tandospirone suppress L-DOPAinduced dyskinesia in MPTP-treated primates (Bibbiani et al., 2001) and in patients with PD (Kannari et al., 2002), respectively. 5-HT1b and 5-HT2 receptors are distributed extensively in basal ganglia, particularly in substantia nigra (Bruinvels et al., 1993). 5-HT1b receptors act as presynaptic heteroreceptors having a facilitatory effect on dopamine (DA) release, but they also inhibit the release of DA from striatal synaptosomes (Sarhan et al., 1999, 2000). 5-HT2 systems are similarly involved in the regulation of motor activity because 5 -HT2 $(2 \mathrm{a} / 2 \mathrm{c})$ receptor agonists such as ( \pm )-2,5-dimethoxy-4-iodoamphetamine normalize the overactivity of the direct striatopallidal output pathway in 6-OHDAlesioned rats (Gresch and Walker, 1999). Indeed, 5-HT2c receptors, which are abundant in the nigral and pallidal complex (Abramowski et al., 1995; Eberle-Wang et al., 1997), are upregu- 
lated in 6-OHDA-lesioned rats and in patients with PD (Radja et al., 1993; Fox and Brotchie, 2000). On the basis of current knowledge, 5-HT receptors (5-HT1a, 5-HT1b, and 5-HT2) are now thought to have a significant role in motor complications in $\mathrm{PD}$, including the dyskinesia associated with chronic L-DOPA treatment (Nicholson and Brotchie, 2002).

We set out to determine the reality of the effects of MDMA on motor symptoms in PD by using the MPTP primate model of this disorder. MPTP-treated common marmosets show akinesia or bradykinesia, rigidity, and postural abnormalities characteristic of PD and also display dyskinesia (chorea and dystonia) when treated repeatedly with L-DOPA (Pearce et al., 1995; Treseder et al., 2000; Iravani et al., 2001; Maratos et al., 2001; Smith et al., 2002). We have compared the effects of MDMA on the motor behavior of normal, MPTP-treated, and MPTP-treated, L-DOPA-primed common marmosets exhibiting dyskinesia. To determine the role played by 5 -HT receptors in the actions of MDMA, we studied the effects of a range of 5-HT receptor (5HT1a/1b and 5-HT2) antagonists on the actions of MDMA on motor disability and dyskinesia in response to L-DOPA treatment.

\section{Materials and Methods}

Animals

Adult common marmosets of either sex (Callithrix jacchus; $n=26$ ), weighing between 280 and $380 \mathrm{gm}$, were used in this study. Marmosets were housed either in pairs or individually at a temperature of $25 \pm 1{ }^{\circ} \mathrm{C}$ with $50 \%$ relative humidity on a $12 \mathrm{hr}$ light/dark cycle. Animals were fed once daily on a diet of fresh fruit, nuts, Mazuri food pellets, and a supplement of vitamin D3 and had ad libitum access to water. On experimental days, the animals were fed after completion of behavioral testing. Three groups of animals were used. In group 1 , all animals were normal and drug naive $(n=4 ; 3$ males and 1 female). Group 2 animals were MPTP treated but had not been exposed to L-DOPA or other dopaminergic agents ( $n=16 ; 8$ males and 8 females). In group 3, marmosets were MPTP treated and primed for dyskinesia after a chronic L-DOPA/ $S$-(-)- $\alpha$-hydrazino-3,4-dihydroxy-2-methylbenzenepropanoic acid (carbidopa) regime ( $n=6 ; 3$ males and 3 females).

\section{MPTP treatment}

Marmosets $(n=22)$ were treated with 1-methyl-4-phenyl-1,2,3,6tetrahydropyridine hydrochloride (MPTP-HCl) (Research Biochemicals International; $2.0 \mathrm{mg} / \mathrm{kg}$, s.c.; dissolved in $0.9 \%$ sterile saline) daily for 5 consecutive days. This treatment regimen induces a persistent and stable syndrome of akinesia, bradykinesia, rigidity, postural abnormality, incoordination, and postural tremor (Jenner and Marsden, 1986; Pearce et al., 1995). Animals were hand-fed on a mixture of Mazuri marmoset jelly, dried milk, and pureed bananas until body weight had returned to pretreatment levels.

After the last administration of MPTP, all animals showed marked motor deficits, displaying an abnormal hunched posture, akinesia, rigidity, loss of vocalization, and postural tremor. Five weeks after MPTP treatment, the animals had recovered some motor function and were able to independently groom, feed, and drink. Experiments were performed in accordance with the Animals (Scientific Procedures) Act 1986 and Home Office regulations (license PPL 3563).

\section{Priming for dyskinesia induction}

Eight weeks after MPTP treatment, some animals $(n=6)$ were treated for $56 \mathrm{~d}$ with $12.5 \mathrm{mg} / \mathrm{kg}$ L-DOPA methyl ester plus $12.5 \mathrm{mg} / \mathrm{kg}$ carbidopa by oral gavage on a daily basis. Carbidopa was administered $30-45 \mathrm{~min}$ before L-DOPA treatment (Pearce et al., 1995). When animals became dyskinetic (between 28 and $56 \mathrm{~d}$ ), daily dosing with a combination of L-DOPA/carbidopa was changed to a once a week treatment. At this point and on, once a week L-DOPA/carbidopa treatment produced a level of dyskinesia similar to that produced at the end of the daily priming period.
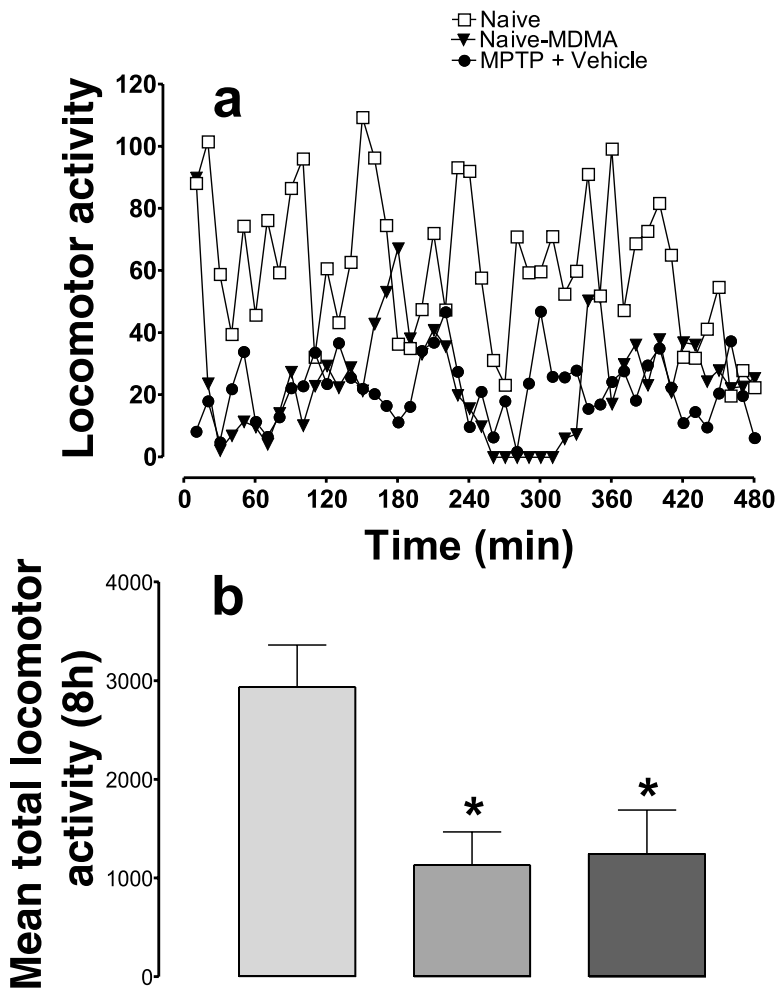

b

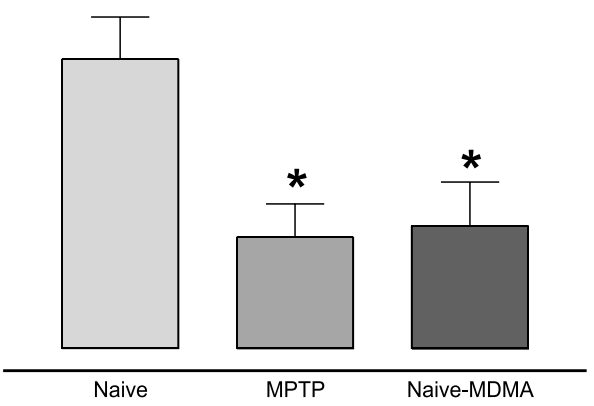

Treatment groups

Figure 1. The effect of MDMA on locomotor activity. MDMA (12 mg/ $/ \mathrm{kg})$ administration led to a long-lasting inhibition of locomotor activity in both normal (drug naive) and MPTP-treated, L-DOPA-unprimed common marmosets compared with normal vehicle-treated common marmosets ( $a$ ). Comparison of the mean motor activity over a period of $8 \mathrm{hr}$ shows a significant MDMA-mediated inhibition of motor activity in both MPTP-treated (L-DOPA unprimed) and normal (drug naive) common marmosets. ${ }^{*} p<0.05(n=4-6)$.

\section{Experimental design}

MDMA effects on motor activity. After acclimatization in the test cages for a period of $30 \mathrm{~min}$, the basal motor activity of the normal animals $(n=4)$ was compared with that of MPTP-treated $(n=16)$ and MPTP-treated, L-DOPA-primed $(n=6)$ animals and monitored for a period of $8 \mathrm{hr}$. To study the effects of MDMA on motor activity and motor disability, a single dose of MDMA per experimental day in the range of 3-12 mg/kg (dissolved in $10 \% \mathrm{w} / \mathrm{v}$ sucrose, p.o.) was administered in the absence of L-DOPA. Whenever MDMA was administered, there was $4-7 \mathrm{~d}$ washout period between treatments.

Effects of MDMA on motor disability and dyskinesia. The effects of MDMA on L-DOPA-induced changes in motor activity, motor disability, and dyskinesia (chorea and dystonia) were studied. L-DOPA-primed, MPTP-treated animals $(n=6)$ were coadministered with either 12.5 $\mathrm{mg} / \mathrm{kg} \mathrm{L}$-DOPA plus 10\% sucrose or L-DOPA plus MDMA 30-45 min after $12.5 \mathrm{mg} / \mathrm{kg}$ carbidopa administration. To determine whether the effects of MDMA on L-DOPA-induced dyskinesia were dose dependent, in a series of experiments the dose of L-DOPA was increased to $25 \mathrm{mg} / \mathrm{kg}$. Furthermore, to assess the selectivity of the effect of MDMA on L-DOPAinduced motor behaviors, in another series of experiments the effects of MDMA on the motor effects produced by a single dose of the DA D3/D2 agonist 2-amino-4,5,6,7-tetrahydro-6-propyl-amino-benzthiazoledihydrochloride (pramipexole) (60 $\mu \mathrm{g} / \mathrm{kg}$, p.o) plus $1 \mathrm{mg} / \mathrm{kg} 4$-(5-chloro-2oxo-1-benzimidazolinyl)-1-[3-(2-oxobenzimidazolinyl)propyl]piperidine) (domperidone), used as an anti-emetic, was determined. To investigate the interaction of MDMA with the selective 5-HT reuptake inhibitor (SERT), (E)-5-methoxy-1-[4-(trifluoromethyl)phenyl]-1-pentanone-O-(2-aminoethyl)oxime maleate (fluvoxamine) $(5 \mathrm{mg} / \mathrm{kg}$ ) was administered at the same time as carbidopa before the coadministration of L-DOPA and MDMA. 

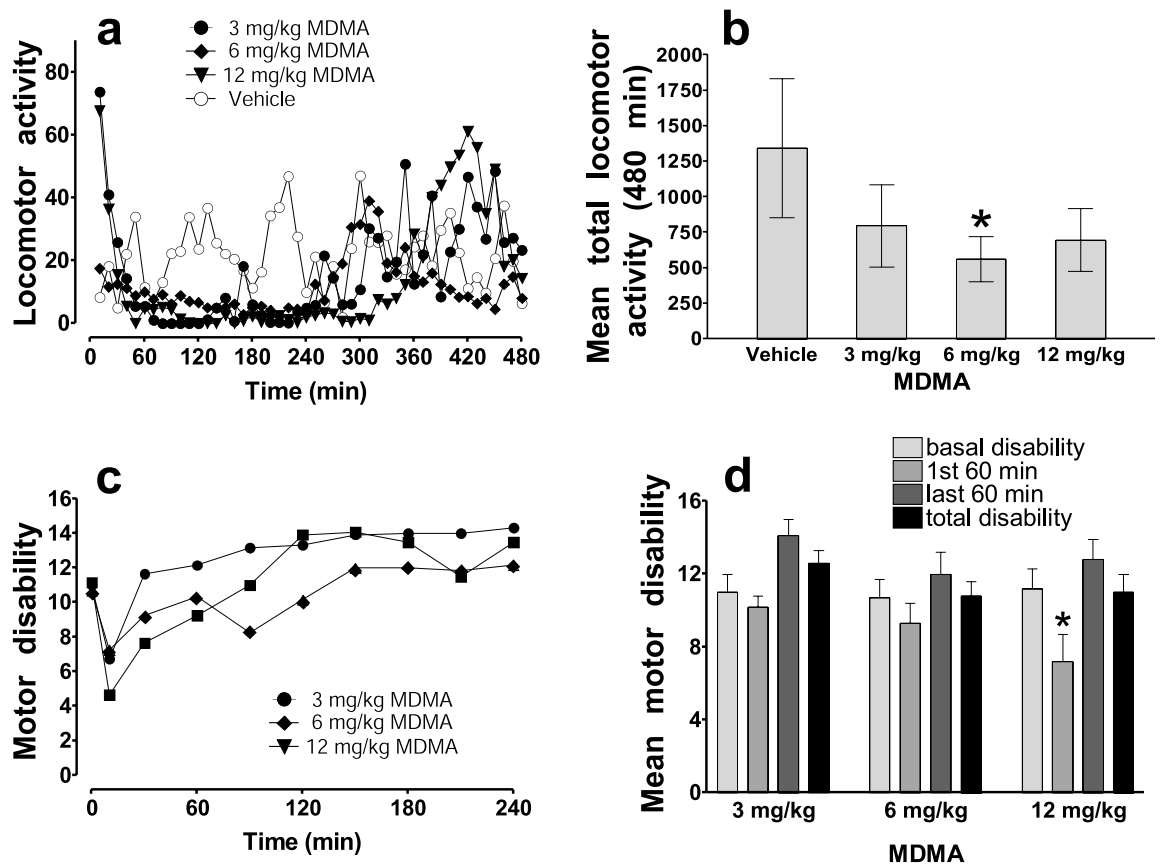

Figure 2. Dose-dependent effect of MDMA on motor activity $(a, b)$ and motor disability $(c, d)$ in MPTP-treated, L-DOPA-primed common marmosets. MDMA dose dependently inhibited the motor activity over a period of $8 \mathrm{hr}$, but compared with control (MPTP treated, L-DOPA-primed) animals, only at $6 \mathrm{mg} / \mathrm{kg}$ was the effect of MDMA on motor activity statistically significant $\left({ }^{*} p<0.05\right)$. MDMA only transiently improved motor disability (c). d, Mean motor disability in 60 min segments. MDMA (12 mg/kg) significantly $(p<0.05)$ improved motor disability during the first 60 min after its administration; thereafter motor disability was not different or it worsened compared with control.

Effects of 5-HT1 and 5-HT2 receptor antagonists on MDMA effects in the presence of $L-D O P A$. To assess the contribution 5-HT1 or 5-HT2 receptors to the effects of MDMA, a range of 5-HT1 or 5-HT2 receptor antagonists were administered at the same time as carbidopa $30 \mathrm{~min}$ before MDMA and L-DOPA administration. (S)-N-tert-butyl-3-(4-(2-methoxyphenyl)piperazin-1-yl)-2-phenylpropanamide dihydrochloride (WAY-100135) (4 $\mathrm{mg} / \mathrm{kg}$, s.c.), a selective 5-HT1a, 3-[3-(dimethylamino)propyl]-4-hydroxy$N$-[4-(4-pyridinyl)phenyl]benzamide dihydrochloride (GR-55562) (5 mg/ $\mathrm{kg}$, s.c.), a selective 5-HT1b, or (S)-1-(1H-indol-4-yloxy)-3-[(1-methylethyl)amino]-2-propanol (S-(-)-pindolol) (2 $\mathrm{mg} / \mathrm{kg}$, s.c.), a mixed 5 -HT1a/b receptor antagonist, and the 5-HT2 receptor antagonist 6-methyl1-(1-methylethyl)ergoline-8 $\beta$-carboxylic acid 2-hydroxy-1-methylpropyl ester maleate (LY-53857) (5 mg/kg, s.c.) were used. A washout period of 7-10 d was allowed between experiments.

Effects of 5-methoxy-3-(1,2,5,6-tetrahydro-4-pyridinyl)-1H-indole hemisuccinate on motor effects of $L-D O P A$. To investigate the contribution of 5-HT1 activation and its possible interaction with the actions of L-DOPA, the effects of the nonselective 5-HT1b/1a agonist 5-methoxy-3-(1,2,5,6tetrahydro-4-pyridinyl)-1 $H$-indole hemisuccinate (RU-24969) (3 mg/ $\mathrm{kg}$, s.c.) on L-DOPA-induced motor activity, motor disability and dyskinesia was studied. RU-24969 was administered subcutaneously, at the same time as carbidopa, $30 \mathrm{~min}$ before treatment with $12.5 \mathrm{mg} / \mathrm{kg}$ L-DOPA using MPTP-treated, L-DOPA-primed marmosets.

\section{Behavioral assessment}

Motor activity. Motor activity was measured in test cages equipped with an array of eight infrared photo sensors (Perspex fronted aluminum cages; $50 \times 60 \times 70 \mathrm{~cm}$ ). The number of beam interruptions attributable to movement was counted and summed in bins of 10 min intervals using an analog to digital converter attached to an Intel-based PC. Motor activity was measured over a period of $6 \mathrm{hr}$ and expressed as time course measuring the number of beam interruption occurring in $10 \mathrm{~min}$ time segments or as the total number of beam interruptions over the test period.

Motor disability. The following observer rating scale was used to assess motor disability each day: alertness $(0-2)$; checking movements $(0-2)$; posture $(0-4)$; balance $(0-3)$; motility $(0-2)$; reactions to stimuli $(0-3)$ and vocalization $(0-$ $2)$. The disability score was obtained by addition of individual scores for each parameter observed. Score zero indicates a normal score, and score 18 indicates a maximum motor disability. On experimental days, motor disability was scored every 10-20 min for a period of up to $240 \mathrm{~min}$. The motor disability scores were either presented graphically as time course graphs or expressed as the mean total disability for each experimental day.

Dyskinesia. Abnormal movements after chronic L-DOPA treatment, in the form of chorea (rapid random flicking movements) and dystonia (abnormal sustained posturing), were scored by observer rating. Each parameter was scored on a scale of 0 (absence of dyskinesia) to 4 (marked continuous dyskinetic activity replacing normal behavior) as reported previously (Pearce et al., 1995). Measurement of dyskinesia consisting of a combination of chorea and dystonia was also scored. This was again rated on a scale of $0-4$. Dystonia, chorea, and dyskinesia scoring was performed simultaneously with motor disability, when animals were being monitored for motor activity.

\section{Drugs}

MDMA (ecstasy), MPTP-HCl, (S)-(-)pindolol, GR-55562, LY-53857, domperidone, and L-DOPA were obtained from Sigma (Poole, UK). WAY100135 and RU-24969 were obtained from Tocris-Cookson (Bristol, UK). Pramipexole was a gift from Upjohn-Pharmacia (Kalamazoo, MI). Fluvoxamine was a gift from Solvay Pharmaceuticals (Weesp, Netherlands). Carbidopa was a gift from Merck, Sharp \& Dohme (Rahway NJ). LY-53857, WAY-100135, GR-55562, and pindolol were dissolved in dimethyl sulfoxide; RU-24969 was dissolved in saline. All antagonists and RU-24969 were administered subcutaneously. All other drugs were dissolved in deionized water containing $10 \%$ sucrose and administered orally. In experiments using pramipexole, animals were pretreated $30 \mathrm{~min}$ before administration of pramipexole with a single oral dose of domperidone $(5 \mathrm{mg} / \mathrm{kg})$ as an anti-emetic. Carbidopa and domperidone were given as suspension in deionized water and $10 \%$ sucrose.

\section{Data analysis}

Results are expressed as mean \pm SEM. Data from motor activity were analyzed using a repeated measures one-way ANOVA for comparison of the effect of different doses of MDMA with vehicle-treated controls at each time point. On obtaining a significant $F$ value, a Newman-Keuls multiple comparison test was performed. The nonparametric motor disability, chorea, and dystonia scores were compared using Freidman's test followed by Dunn's multiple comparison test.

\section{Results}

\section{Basal motor activity}

The motor behavior of normal, MPTP-treated, or MPTP-treated, L-DOPA-primed common marmosets did not qualitatively differ from that exhibited in their home cage environment when placed into the activity monitors. MPTP-treated animals exhibited akinesia or bradykinesia, a hunched posture, reduced reaction to external stimuli, a reduction in vocalization, and head checking. The total motor activity for MPTP-treated animals was significantly less than for normal marmosets (total activity counts per $8 \mathrm{hr}$, normal group: $2941 \pm 532, n=4$; MPTP L-DOPA: $1135 \pm 336, n=16$; MPTP L-DOPA primed: $1261 \pm 397, n=$ $6 ; p<0.05)$. 

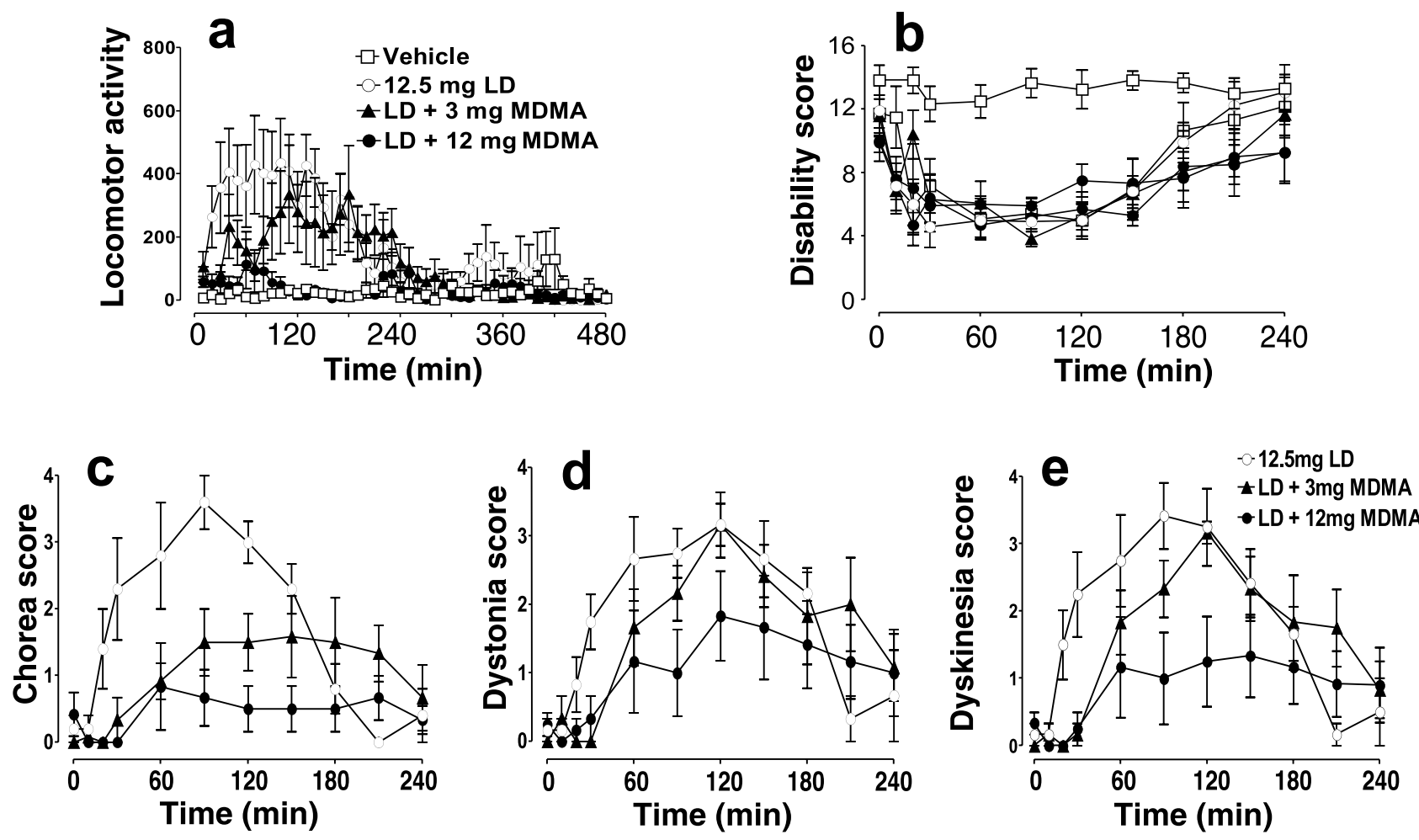

Figure 3. The effects of MDMA on motor activity $(a)$, motor disability $(b)$, and dyskinesia $(c-e)$ in MPTP-treated, L-DOPA-primed common marmosets treated with a combination of 12.5 mg/kg L-DOPA and $12.5 \mathrm{mg} / \mathrm{kg}$ carbidopa. In L-DOPA/carbidopa-treated animals, MDMA at 3-12 mg/kg dose dependently inhibited locomotor activity ( $a$ ) but did not affect the ability of L-D0PA/carbidopa treatment in affecting motor disability $(b)$. Administration of L-DOPA in primed marmosets led to a robust expression of dyskinesia ( $c$ ) consisting of chorea ( $d$ ) and dystonia ( $e$ ). MDMA concentration dependently inhibited dyskinesia, chorea, and dystonia.

Effect of MDMA on motor activity of normal common marmosets

Within $10 \mathrm{~min}$ of MDMA (12 mg/kg) administration to normal common marmosets, there was a brief and modest burst of motor activity in all animals but no other obvious beneficial changes in these animals. Between 15 and 20 min, however, investigatory head checking movements were reduced and vocalization decreased. MDMA $(12 \mathrm{mg} / \mathrm{kg})$ treatment resulted in a significant reduction of total motor activity $(p<0.05)$ (Fig. $1 b)$. The level of motor activity in normal marmosets after MDMA was now similar to that observed in MPTP-treated marmosets (Fig. 1a,b).

Three of four animals exhibited low-frequency lateral head movements, and in one animal marked abnormal oral movement in the form of high-frequency "jaw chattering" was observed. These abnormal behaviors were brought about within 30-45 min of MDMA administration and lasted for an additional $30 \mathrm{~min}$.

\section{Effect of MDMA on motor activity of MPTP-treated} common marmosets

In MPTP-treated marmosets $(n=6)$, administration of MDMA (3-12 mg/kg, p.o.) produced a transient dose-dependent increase in motor activity and improvement in motor disability. The maximal effect was within 10 min of MDMA administration but subsided by 45-60 min; however, only at the highest dose tested was there a statistically significant improvement in motor disability. This transient effect after MDMA administration was followed by a dose-dependent reduction in motor activity and worsening of motor disability (Fig. 2).
Effects of MDMA on L-DOPA-induced changes in motor behavior in L-DOPA-primed common marmosets

Administration of L-DOPA (12.5 mg/kg, p.o.) to MPTP-treated, L-DOPA-primed marmosets produced a marked increase in motor activity and reversal of motor disability, which included improvements in posture, vocalization, response to external auditory stimuli, and head-checking movement. Within 15-30 min of L-DOPA administration, peak dose dyskinesia appeared and was maximal between 60 and $90 \mathrm{~min}$. Administration of MDMA (3-12 $\mathrm{mg} / \mathrm{kg}$ ) caused a dose-dependent reduction of motor activity induced by L-DOPA treatment (L-DOPA from $6851 \pm 1221$ counts $/ 4$ hr to $4954 \pm 1050$ counts $/ 4 \mathrm{hr}, p<0.05$, and $1081 \pm 370$ counts $/ 4 \mathrm{hr}, p<0.001$ ) (Fig. $3 a$ ). The MDMA (12 mg/kg)induced decrease in motor activity shown by MPTP-treated marmosets after administration of L-DOPA $(12 \mathrm{mg} / \mathrm{kg})$ reduced the motor activity to a level not significantly different from that observed in normal common marmosets (normal animals: $1344 \pm$ 389 counts/ 4 hr; $p>0.05$ ). Importantly, MDMA did not modify the ability of L-DOPA to reduce motor disability (L-DOPA, mean disability per $4 \mathrm{hr}: 54 \pm 3.8$; L-DOPA $+12 \mathrm{mg} / \mathrm{kg}$ MDMA: $52 \pm$ $6.5 ; p>0.05$ ) (Fig. 3b); however, MDMA dose dependently reduced the dyskinesia induced by L-DOPA administration (total dyskinesia per $4 \mathrm{hr}$, L-DOPA: $19 \pm 1.5$; L-DOPA $+3 \mathrm{mg} / \mathrm{kg}$ MDMA: $13.9 \pm 1.9 ; \mathrm{L}-\mathrm{DOPA}+12 \mathrm{mg} / \mathrm{kg}$ MDMA: $7.8 \pm 2.9)$ (Fig. 3c). MDMA reduced the mean intensity of L-DOPAinduced chorea from $18.3 \pm 3.3$ to $9.3 \pm 2.0$ and $4.0 \pm 1.3$ at the doses of 3 and $12 \mathrm{mg} / \mathrm{kg}$, respectively $(p<0.001)$ (Fig. $3 d$ ). L-DOPA-induced dystonia was only significantly reduced at the highest dose of MDMA tested (mean total dystonia per $4 \mathrm{hr}$ : 

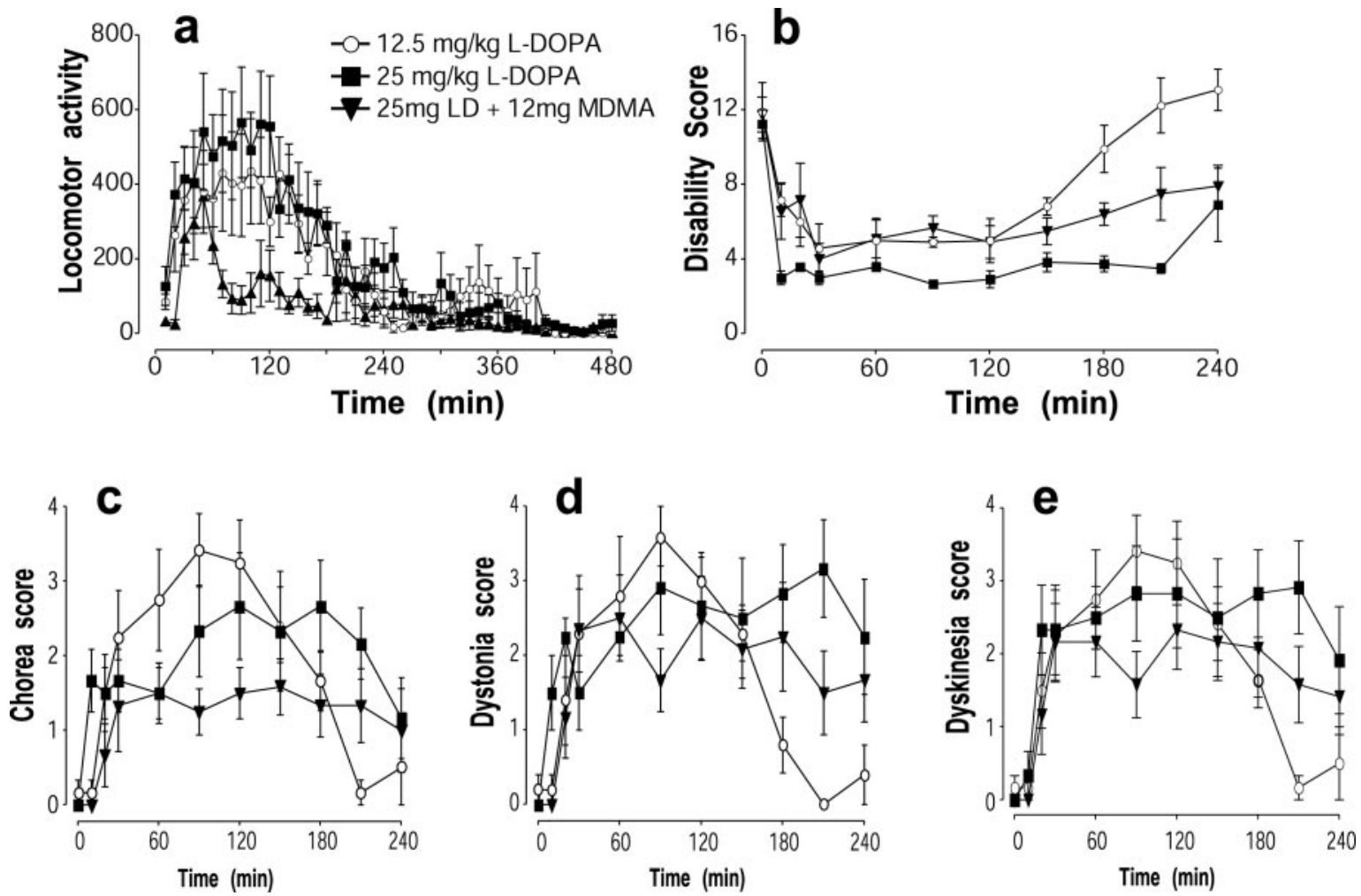

Figure 4. The effect of MDMA on motor activity ( $a$ ), motor disability ( $b$ ), chorea ( $c$, dystonia ( $d$ ), and dyskinesia (e) induced by a high dose of L-DOPA ( $25 \mathrm{mg} / \mathrm{kg})$ in the presence of $12.5 \mathrm{mg} / \mathrm{kg}$ carbidopa. Doubling the concentration of L-DOPA did not increase the motor activity significantly but led to a partial reversal of the inhibitory effect of MDMA (12 mg/kg). There was an earlier expression of motor disability and dyskinesia after the doubling of the L-DOPA dose, and a partial reversal of the anti-dyskinetic effect of MDMA.

L-DOPA, $14.2 \pm 3.3$; L-DOPA + MDMA, $9.6 \pm 3.7 ; p<0.05)$

(Fig. 3e).

Total motor activity was increased after administration of L-DOPA $25 \mathrm{mg} / \mathrm{kg}$, but this was not significantly different compared with the effect of L-DOPA $12.5 \mathrm{mg} / \mathrm{kg}$ (motor activity per 8 hr: $12.5 \mathrm{mg} / \mathrm{kg}, 6851 \pm 1221 ; 25 \mathrm{mg} / \mathrm{kg}, 8559 \pm 1041 ; p>0.05)$. Administration of MDMA $12 \mathrm{mg} / \mathrm{kg}$ reduced the increase in motor activity produced by $25 \mathrm{mg} / \mathrm{kg}$ L-DOPA ( $25 \mathrm{mg} / \mathrm{kg} \mathrm{L-DOPA} \mathrm{+}$ 12 mg/kg MDMA: $2994 \pm$ 594) (Fig. 4a); however, MDMA 12 $\mathrm{mg} / \mathrm{kg}$ did not alter the dyskinesia induced by administration of L-DOPA $25 \mathrm{mg} / \mathrm{kg}$ (chorea: $25 \mathrm{mg} / \mathrm{kg}$ L-DOPA, $16.5 \pm 3.8,25$ $\mathrm{mg} / \mathrm{kg}$ L-DOPA + $12 \mathrm{mg} / \mathrm{kg}$ MDMA, $10.8 \pm 2.6$; $p>0.05$; dystonia: $25 \mathrm{mg} / \mathrm{kg}$ L-DOPA $20.1 \pm 4.4,25 \mathrm{mg} / \mathrm{kg} \mathrm{L-DOPA}+12$ $\mathrm{mg} / \mathrm{kg}$ MDMA, $16.5 \pm 3.9 ; p>0.05$; total dyskinesia: $25 \mathrm{mg} / \mathrm{kg}$ L-DOPA: $20.7 \pm 4.5 ; 25 \mathrm{mg} / \mathrm{kg}$ L-DOPA $+12 \mathrm{mg} / \mathrm{kg}$ MDMA: $15.5 \pm 3.6 ; p>0.05)$. The beneficial effects of L-DOPA $25 \mathrm{mg} / \mathrm{kg}$ on motor disability was unaltered by MDMA $12 \mathrm{mg} / \mathrm{kg}$.

Effects of MDMA on motor activity produced by the D2/D3 agonist pramipexole in MPTP-treated, L-DOPA-primed common marmosets

Administration of pramipexole $(60 \mu \mathrm{g} / \mathrm{kg})$ to MPTP-treated, L-DOPA-primed common marmosets caused a marked increase in motor activity, improvement in motor disability, and induced dyskinesia in L-DOPA-primed, MPTP-treated marmosets that was of long duration (Fig. 5). MDMA (3-12 mg/kg) dose dependently reduced the increase in motor activity and reduced dyskinesia, including both chorea and dystonia, without reversing the improvement in motor disability produced by pramipexole (Fig. 5).
Effect of fluvoxamine on MDMA-induced changes in L-DOPA-treated motor behavior in MPTP-treated, L-DOPA-primed common marmosets

In L-DOPA-primed marmosets, fluvoxamine ( $5 \mathrm{mg} / \mathrm{kg}$, administered 30 min previously) did not affect the increase in motor activity or reverse motor disability or the intensity of dyskinesia induced by the administration of $12.5 \mathrm{mg} / \mathrm{kg} \mathrm{L}-\mathrm{DOPA}$; however, fluvoxamine almost completely prevented the inhibition of L-DOPA-induced motor activity and suppression of dyskinesia produced by $12 \mathrm{mg} / \mathrm{kg}$ MDMA. Motor activity and dyskinesia in the presence of the combination of L-DOPA, MDMA, and fluvoxamine were not significantly different from that produced by administration of $12.5 \mathrm{mg} / \mathrm{kg}$ L-DOPA alone (dyskinesia per $4 \mathrm{hr}$ : L-DOPA + MDMA $12 \mathrm{mg} / \mathrm{kg}, 7.8 \pm 2.9$; dyskinesia: L-DOPA + MDMA $12 \mathrm{mg} / \mathrm{kg}$ + fluvoxamine, $11.6 \pm 2.6$; L-DOPA + fluvoxamine, $14.1+3.1$ ) (Fig. 6).

Effects of 5-HT1 and 5-HT2 antagonists on MDMA-induced changes in L-DOPA-treated motor behavior in MPTP-treated, L-DOPA-primed common marmosets

Administration of the $5 \mathrm{HT} 1 \mathrm{a}$ or $5-\mathrm{HT} 1 \mathrm{~b}$ receptor antagonists WAY-100135 (4 mg/kg) or GR-55562 (5 mg/kg), respectively, resulted in a trend toward the reversal of the effects of MDMA on L-DOPA-induced motor activity, motor disability, and dyskinesia. Both antagonists significantly reversed the $12 \mathrm{mg} / \mathrm{kg}$ MDMAinduced suppression of locomotor activity and dyskinesia at the concentrations used (chorea and dystonia) (Table 1, Fig. 7). GR$5562(5 \mathrm{mg} / \mathrm{kg})$ but not WAY-100135 (4 mg/kg) significantly reversed the beneficial effects of $12 \mathrm{mg} / \mathrm{kg}$ MDMA plus 12.5 mg/kg L-DOPA (Table 1, Fig. 7). Administration of a nonselective 

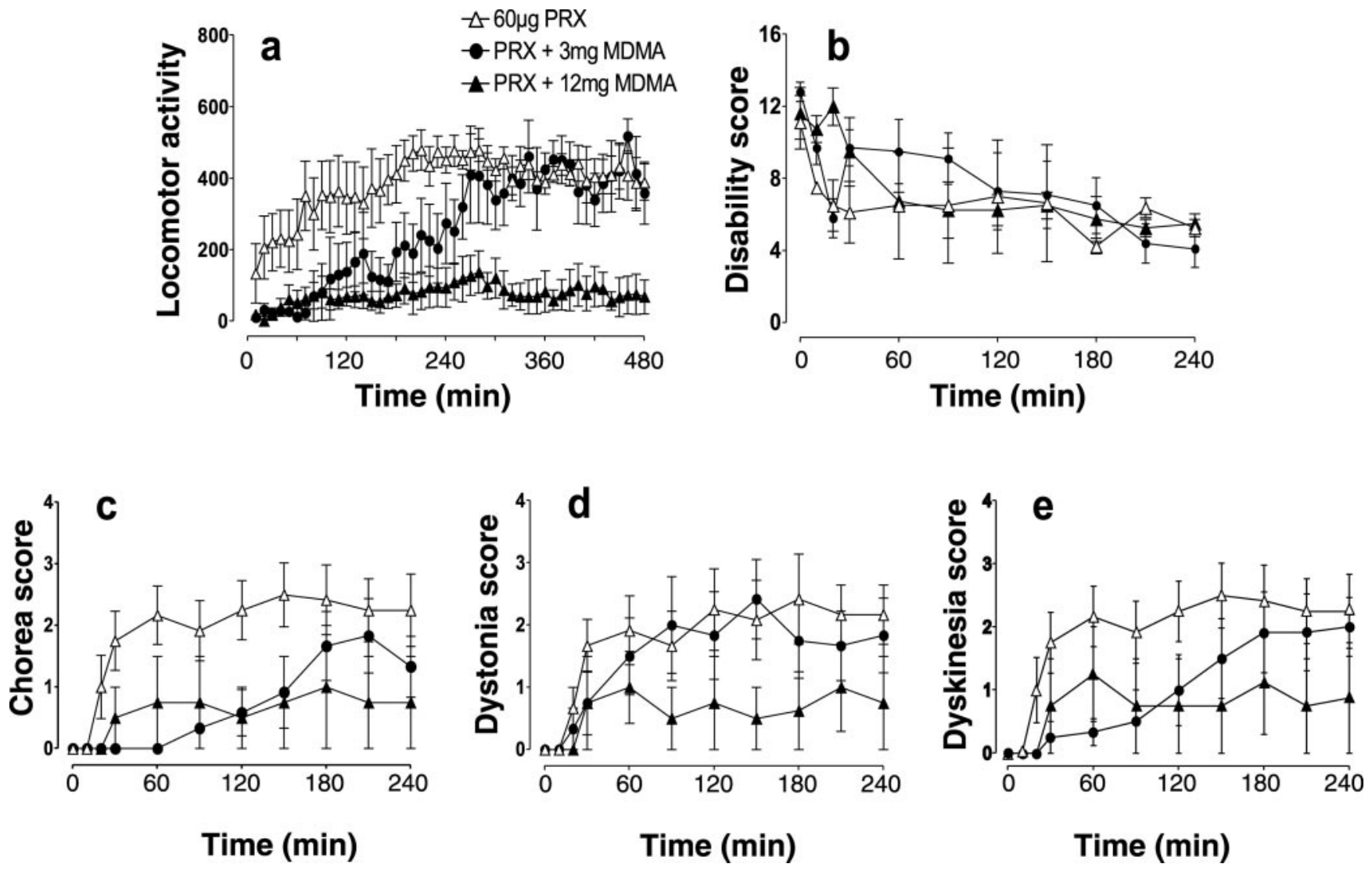

Figure 5. The effects of MDMA on motor activity $(a)$, motor disability $(b)$, chorea $(c)$, dystonia $(d)$, and dyskinesia (e) in MPTP-treated, L-DOPA-primed common marmosets treated with the selective D2/D3 agonist pramipexole (60 $\mu \mathrm{g} / \mathrm{kg}$ ). Pramipexole treatment led to a prolonged increase in locomotor activity $(a)$ and improvement in motor disability $(b)$. MDMA dose-dependently inhibited motor activity but did not affect the ability of pramipexole in reducing motor disability. Dyskinesia, chorea $(c)$, and dystonia ( $d$ ) were dose-dependently inhibited by MDMA.

5-HT1a/b antagonist $2 \mathrm{mg} / \mathrm{kg} S$ - $(-)$-pindolol led to a reversal of MDMA-induced inhibition motor activity in L-DOPA-treated common marmosets but did not significantly alter the effects of MDMA on L-DOPA-induced dyskinesia or motor disability (Table 1).

Administration of a 5-HT2 receptors antagonist, LY-53857 (5 $\mathrm{mg} / \mathrm{kg}$ ), significantly improved the MDMA (12 mg/kg)-induced suppression of L-DOPA $(12.5 \mathrm{mg} / \mathrm{kg})$-mediated motor activity (Fig. 7d). This treatment did not affect the motor disability, however, nor did it reduce the ability of MDMA to suppress L-DOPAinduced dyskinesia (Table 1, Fig. 7e,f).

\section{Effects of 5-HT1a,b agonist RU-24969 on L-DOPA-induced changes in motor activity}

Administration of L-DOPA (12.5 mg/kg) and RU24969 (3 mg/ $\mathrm{kg}$ ) had a debilitating effect on motor activity (Table 1). All MPTP-treated, L-DOPA-primed marmosets after RU24969 treatment displayed a trembling gait and abnormal posture consisting of elevated hindquarter and lowered head and a frozen facial expression. Furthermore, MPTP animals exhibited a marked degree of total body and limb tremor, although motor activity was not significantly different from that observed with MDMA (12 mg/kg) and L-DOPA treatment, but the motor behavior and posture were qualitatively different, although none of the animals displayed any dyskinesia.

\section{Discussion}

Dyskinesia can become a limiting factor in the long-term treatment of PD using L-DOPA. This study shows that MDMA can reverse L-DOPA-induced dyskinesia and reduce motor activity shown by L-DOPA-primed common marmosets in response to L-DOPA to the levels observed in normal animals. This investigation also shows that inhibition of SERT by fluvoxamine completely inhibited the effects of MDMA on locomotor activity, as well as the expression of dyskinesia (both dystonia and chorea). These data from MPTP-treated animals and those observations made in normal common marmosets suggest that the effects of MDMA are unlikely to be mediated by dopaminergic mechanisms.

In normal common marmosets, administration of a relatively high MDMA dose $(12 \mathrm{mg} / \mathrm{kg})$ did not increase motor activity in contrast to the effects of other dopaminergic agents such as $(+)$ amphetamine (Scraggs and Ridley, 1978). Instead, MDMA produced a long-lasting suppression of motor activity and disruption of the normal motor behavior that consisted of reduced head checking, inhibition of vocalization, and attenuation of responses to external audio stimuli. Other behaviors were also exhibited, for example, head weaving and teeth chattering reminiscent of a 5-HT ("serotonin") syndrome (Green et al., 1995). This suggests the dominance of the effect of MDMA on serotoninergic transmission in the presence of an intact dopaminergic system in normal common marmosets. The effects in common marmosets contrast with the effects of MDMA in rats that result in motor hyperactivity localized to the periphery of the test chamber (Paulus and Geyer, 1992; Rempel et al., 1993). Hyperactivity in rats produced by MDMA has been associated with increased brain levels of 5-HT, because inhibition of 5-HT synthesis by 

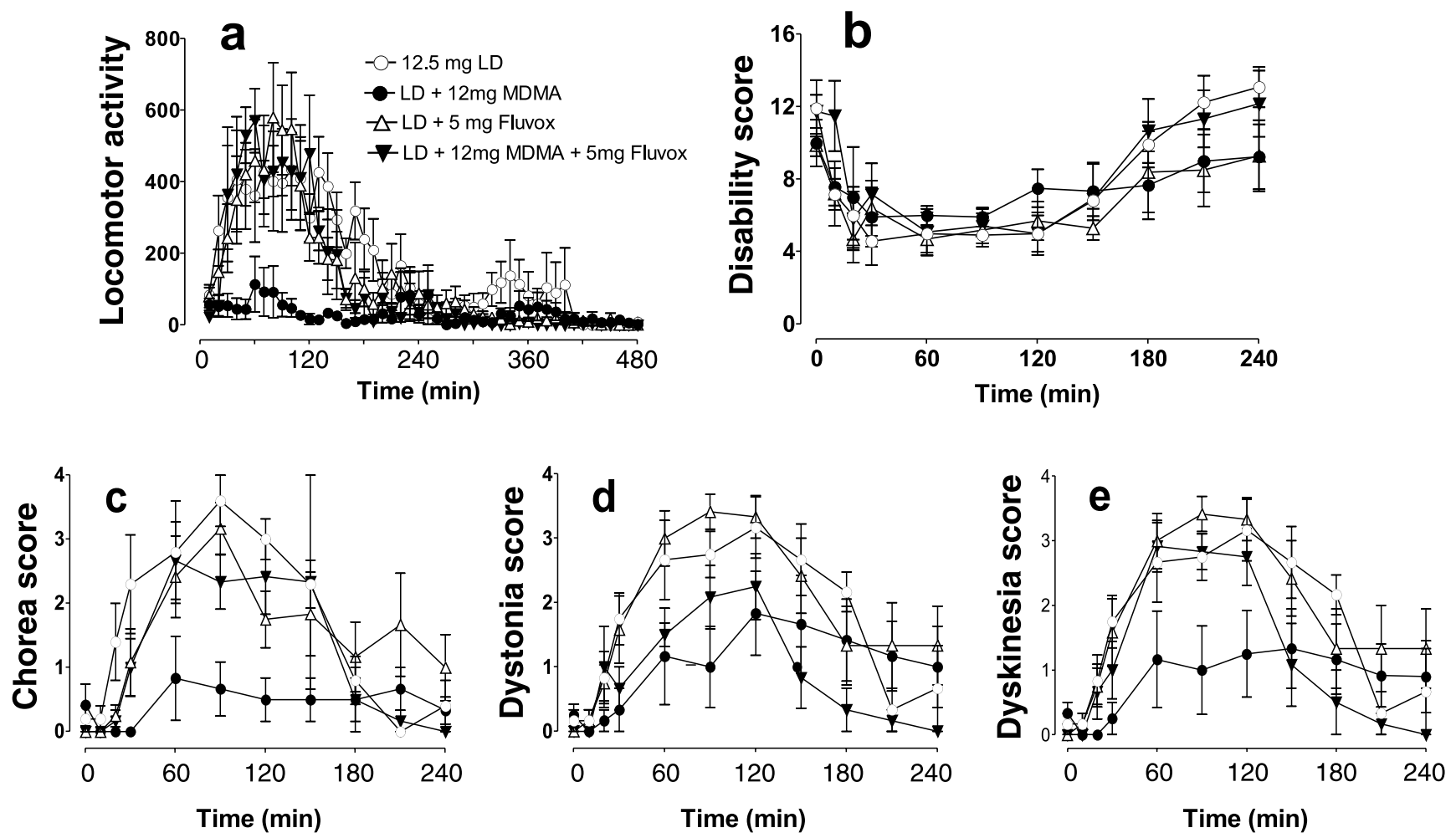

Figure 6. The effect of the serotonin reuptake inhibitor fluvoxamine ( $5 \mathrm{mg} / \mathrm{kg}$ ) on motor activity ( $a)$, motor disability $(b)$, chorea ( $(c)$, dystonia $(d)$, and dyskinesia (e) in L-DOPA-primed common marmosets treated with a combination of L-DOPA/carbidopa $(12.5 \mathrm{mg} / \mathrm{kg})$ and MDMA $(12 \mathrm{mg} / \mathrm{kg})$. Treatment with fluvoxamine in the presence of L-DOPA and MDMA blocked the inhibitory effect of MDMA on locomotor activity and dyskinesia [chorea $(c)$; dystonia $(d)$ ] but failed to affect the effect of L-DOPA in improving motor disability $(b)$.

Table 1. The effects of serotoninergic agents on L-Dopa-induced changes in motor behavior in L-Dopa-primed, MPTP-treated common marmosets

\begin{tabular}{|c|c|c|c|c|}
\hline Treatments & Motor activity & Motor disability & Chorea & Dystonia \\
\hline \multicolumn{5}{|c|}{ (mean total/4hr \pm SEM) } \\
\hline LD alone & $6851 \pm 1221$ & $54 \pm 4$ & $18.3 \pm 3.3$ & $14.2 \pm 3.3$ \\
\hline $\mathrm{LD}+\mathrm{MDMA}(3 \mathrm{mg} / \mathrm{kg})$ & $4945 \pm 1050$ & $55 \pm 4$ & $9.3 \pm 2.0^{*}$ & $13.8 \pm 2.1$ \\
\hline $\mathrm{LD}+\mathrm{MDMA}(12 \mathrm{mg} / \mathrm{kg})$ & $1081 \pm 370^{*}$ & $53 \pm 8$ & $4.0 \pm 1.3^{* *}$ & $9.6 \pm 3.7^{*}$ \\
\hline$L D+M D M A(12 \mathrm{mg} / \mathrm{kg})+\mathrm{LY}-53857(5 \mathrm{mg} / \mathrm{kg})$ & $2476 \pm 770^{* 11}$ & $54 \pm 9$ & $2.2 \pm 1.2^{* *}$ & $7.5 \pm 2.1^{*}$ \\
\hline$L D+$ MDMA $(12 \mathrm{mg} / \mathrm{kg})+\mathrm{S}(-)-$ pindolol $(2 \mathrm{mg} / \mathrm{kg})$ & $2177 \pm 576^{* \Uparrow 1}$ & $50 \pm 8$ & $2.8 \pm 0.4^{* *}$ & $10 \pm 3.0$ \\
\hline LD + MDMA (12 mg/kg) + WAY100135 (4 mg/kg) & $1801 \pm 705^{*}$ & $63 \pm 9$ & $7.0 \pm 2.9^{*}$ & $14.6 \pm 3.1$ \\
\hline LD + MDMA (12 mg/kg) + GR55562 (5 mg/kg) & $2012 \pm 831^{*}$ & $79 \pm 14^{*}$ & $7.0 \pm 3.5^{*}$ & $15.5 \pm 2.9$ \\
\hline LD + RU24962 (3 mg/kg) & $851 \pm 240^{* *}$ & $97 \pm 5^{*}$ & & \\
\hline
\end{tabular}

Comparisons are made with respect to the responses after L-Dopa/carbidopa alone. LD indicates $12.5 \mathrm{mg} / \mathrm{kg} \mathrm{L-Dopa}+12.5 \mathrm{mg} / \mathrm{kg}$ carbidopa. ${ }^{*} p<0.05$; ${ }^{* *} p<0.01 ;{ }^{\mathrm{q}} p<0.05$ with respect to LD $+12 \mathrm{mg} / \mathrm{kg}$ MDMA.

p-chlorophenylalanine attenuated this effect and selective 5-HT reuptake inhibitors blocked this effect (Callaway et al., 1990). In MPTP-treated marmosets, MDMA administration caused an initial brief burst of motor activity and a transient improvement in motor disability that was dose dependent; however, this was followed by a much longer lasting dose-dependent reduction of motor activity. Motor disability was improved briefly by MDMA administration, but subsequently it worsened. There was no correlation between the reduction of motor disability and the suppression of motor activity, so mechanistically they appeared unrelated. Again these effects differ from the marked increase in motor activity and the marked reduction of disability produced by dopaminergic agents administered to MPTP-treated primates (Maratos et al., 2001) and suggest that MDMA is acting through other mechanisms.

In MPTP-treated, L-DOPA-primed common marmosets, administration of L-DOPA readily increased motor activity above that exhibited by normal marmosets and improved motor disability; however, L-DOPA treatment also elicited marked dyski- nesia, consisting predominantly of chorea and dystonia. MDMA administration prevented the increase in L-DOPA-induced motor activity and the onset of dyskinesia but was without effect on the ability of L-DOPA to reduce motor disability. This is highly important because motor hyperactivity and the expression of involuntary movements are related to the long-term treatment complications of $\mathrm{PD}$, whereas reversal of motor disability reflects the desired therapeutic response to L-DOPA.

One explanation for the effects of MDMA may be that it alters the conversion of L-DOPA to DA, because the effects of MDMA in inhibiting dyskinesia and motor activity were overcome by increasing the dose of L-DOPA to $25 \mathrm{mg} / \mathrm{kg}$. MDMA had no effect, however, on L-DOPA-induced improvements in motor disability at either L-DOPA dose, suggesting that its effects were independent of dopaminergic transmission. Indeed, MDMA similarly affected locomotor activity and dyskinesia produced by the DA D2/D3 receptor agonist pramipexole, without influencing the reversal of disability. Because the actions of pramipexole are on postsynaptic DA receptors, it is unlikely that the actions of 
MDMA on the effects of L-DOPA are mediated by alterations of its conversion to DA. This would indicate that MDMA does not affect dopamine levels elevated by L-DOPA.

Rather the effects of MDMA may be linked to its actions on SERT as judged by the effects of the selective 5-HT re-uptake inhibitor fluvoxamine. Indeed, the ability of fluvoxamine treatment to fully block the effects of MDMA on L-DOPA-induced motor actions rules out other potential actions of MDMA. These include its direct effect as an agonist on 5-HT1a/b, 5-HT2a/ b/c receptors (Lyon et al., 1986; Rempel et al., 1993; Geyer, 1996; Granoff and Ashby, 1998; Sprague et al., 1998; Reneman et al., 2002). Our data strongly suggest that the anti-dyskinetic actions of MDMA are mediated through an indirect activation of 5-HT receptors induced by the elevation of extracellular levels of 5-HT (Crespi et al., 1997; Iravani et al., 2000).

Recent evidence suggests that the 5-HT1a agonists sarizotan (Bibbiani et al., 2001) and tandospirone (Kannari et al., 2002) reduce L-DOPA-induced dyskinesia, an effect that was fully reversible on administration of the 5-HT1a antagonist WAY100635 in MPTP-treated primates (Bibbiani et al., 2001). Furthermore, the atypical antipsychotic quetiapine, which possesses $5 \mathrm{HT} 2 \mathrm{a} / \mathrm{c}$ and D2/3 antagonistic activity, substantially reduced L-DOPAinduced dyskinesias when coadministered with L-DOPA in MPTP-treated macaque monkeys (Oh et al., 2002). Thus, it seems likely that 5-HT1 and 5-HT2 receptor subtypes may modulate dyskinesia. In our study, using combinations of 5-HT1 antagonists and MDMA with L-DOPA confirmed, to a large extent, the findings of Bibbiani et al. (2001). Both 5-HT1a and 5-HT1b antagonists WAY-100135 and GR-55562, respectively, reversed the beneficial effects produced by MDMA when given in combination with L-DOPA. Which receptor subtype is involved in the modulation of dyskinesia is not clear, because neither compound is specific in its actions.

In rodents, both MDMA and RU24969 (a relatively nonselective 5-HT1 agonist with a preference for 5-HT1b receptors) increase motor activity, and both drugs are believed to act through 5-HT1b receptors (Rempel et al., 1993). So we investigated the contribution of 5-HT1 receptors to the reduction of the L-DOPAmediated increase in motor activity and to L-DOPA-induced dyskinesia. A combination of L-DOPA and RU24969 markedly disrupted motor activity. MPTP-treated, L-DOPA-primed marmosets treated with RU24969 displayed marked impairment of movement accompanied by postural abnormalities, but importantly, no chorea and dystonia were observed in any animal. The absence of dyskinesia may be a consequence of the activation of 5-HT1a and 5-HT1b receptors by RU24969 and as such will reflect the inhibition of involuntary movement produced by

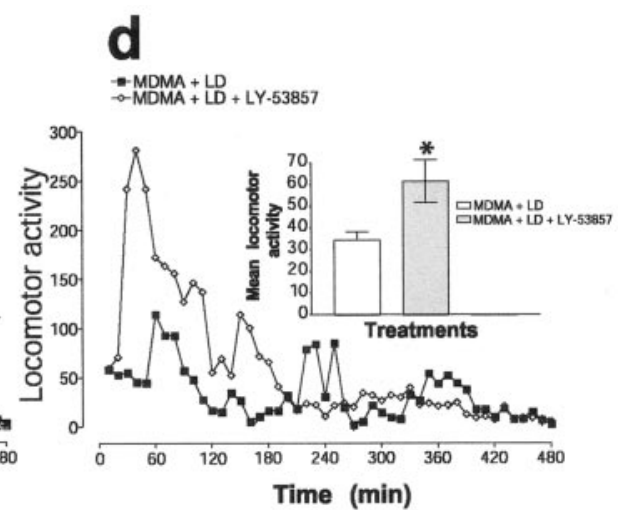

e
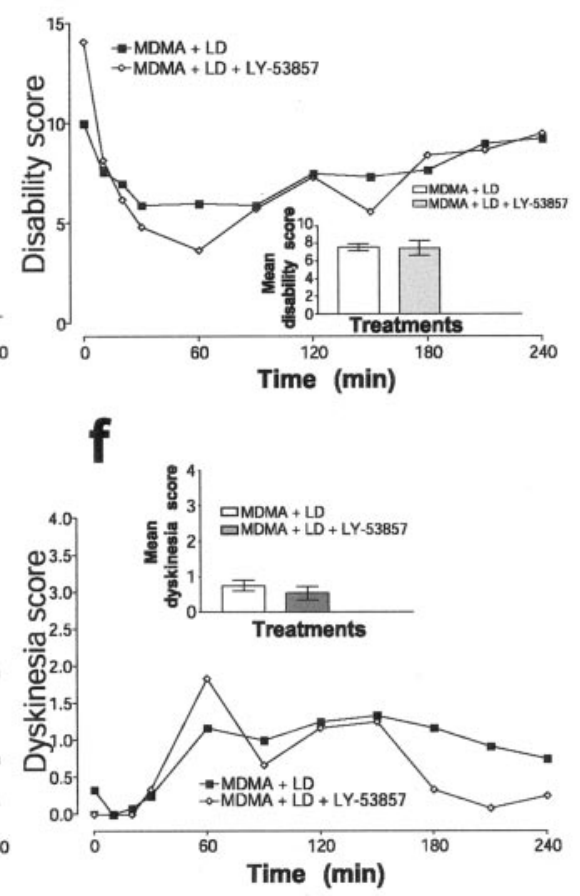

Figure 7. In the presence of the 5-HT1a/b antagonists WAY-100135 (4 mg/kg) and GR-55562 (5 mg/kg) and the 5-HT2 antagonist LY-53857 (5 mg/kg), there was a partial reversal of the inhibitory effect of MDMA $(12 \mathrm{mg} / \mathrm{kg})$ on motor activity in L-DOPA-treated animals $(a, d)\left({ }^{*} p<0.05\right)$. The 5-HT1b antagonist GR-55562, but not the 5-HT1a antagonist WAY-100135, partially reversed motor disability and dyskinesia in animals treated with L-DOPA and MDMA $\left({ }^{*} p<0.05\right)$. The $5-\mathrm{HT} 2$ antagonist LY-53857 failed to affect motor disability and dyskinesia in animals treated with L-DOPA and MDMA.

MDMA. This would signify a common mechanism for inhibition of L-DOPA-induced dyskinesia through $5-\mathrm{HT} 1 \mathrm{a} / \mathrm{b}$ receptors.

Recently it was suggested that the main metabolites of MDMA, including 4-hydroxy-3-methoxymethamphetamine and 3,4-dihydroxyamphetamine, may also stimulate 5-HT1a/b and 5-HT2c receptors as judged by their ability to stimulate oxytocin and vasopressin release (Forsling et al., 2001, 2002; Jorgensen et al., 2003). At present, there are no pharmacological data regarding the actions of metabolites of MDMA on basal ganglia function, but it may be that they contribute significantly to the pharmacological actions of MDMA observed in the MPTPtreated primates in this study.

MDMA will never become a treatment for the complications of PD. The analysis of the pharmacological activity of MDMA responsible for its normalization of motor activity and suppression of dyskinesia strongly implicates $5-\mathrm{HT} 1 \mathrm{a} / 1 \mathrm{~b}$ receptor involvement. Consequently, the development of 5-HT1a/1b recep- 
tor agonists for the treatment of dyskinesia may provide a novel approach to the treatment of PD.

\section{References}

Abramowski D, Rigo M, Duc D, Hoyer D, Staufenbiel M (1995) Localization of the 5-hydroxytryptamine2C receptor protein in human and rat brain using specific antisera. Neuropharmacology 34:1635-1645.

Bankson MG, Cunningham KA (2001) 3,4-Methylenedioxymethamphetamine (MDMA) as a unique model of serotonin receptor function and serotonin-dopamine interactions. J Pharmacol Exp Ther 297:846-852.

Barnes NM, Sharp T (1999) A review of central 5-HT receptors and their function. Neuropharmacology 38:1083-1152.

Bibbiani F, Oh JD, Chase TN (2001) Serotonin 5-HT1A agonist improves motor complications in rodent and primate parkinsonian models. Neurology 57:1829-1834

Bruinvels AT, Palacios JM, Hoyer D (1993) Autoradiographic characterisation and localisation of 5-HT1D compared to 5-HT1B binding sites in rat brain. Naunyn Schmiedebergs Arch Pharmacol 347:569-582.

Callaway CW, Wing LL, Geyer MA (1990) Serotonin release contributes to the locomotor stimulant effects of 3,4-methylenedioxymethamphetamine in rats. J Pharmacol Exp Ther 254:456-464.

Crespi D, Mennini T, Gobbi M (1997) Carrier-dependent and $\mathrm{Ca}(2+)$ dependent 5-HT and dopamine release induced by $(+)$-amphetamine, 3,4-methylendioxymethamphetamine, $p$-chloroamphetamine and (+)fenfluramine. Br J Pharmacol 121:1735-1743.

Eberle-Wang K, Mikeladze Z, Uryu K, Chesselet MF (1997) Pattern of expression of the serotonin $2 \mathrm{C}$ receptor messenger RNA in the basal ganglia of adult rats. J Comp Neurol 384:233-247.

Forsling M, Fallon JK, Kicman AT, Hutt AJ, Cowan DA, Henry JA (2001) Arginine vasopressin release in response to the administration of 3,4methylenedioxymethamphetamine ("ecstasy"): is metabolism a contributory factor? J Pharm Pharmacol 53:1357-1363.

Forsling ML, Fallon JK, Shah D, Tilbrook GS, Cowan DA, Kicman AT, Hutt AJ (2002) The effect of 3,4-methylenedioxymethamphetamine (MDMA, "ecstasy") and its metabolites on neurohypophysial hormone release from the isolated rat hypothalamus. Br J Pharmacol 135:649-656.

Fox SH, Brotchie JM (2000) 5-HT2C receptor binding is increased in the substantia nigra pars reticulata in Parkinson's disease. Mov Disord 15:1064-1069.

Frechilla D, Cobreros A, Saldise L, Moratalla R, Insausti R, Luquin M, Del Rio J (2001) Serotonin 5-HT(1A) receptor expression is selectively enhanced in the striosomal compartment of chronic parkinsonian monkeys. Synapse 39:288-296.

Geyer MA (1996) Serotonergic functions in arousal and motor activity. Behav Brain Res 73:31-35.

Granoff MI, Ashby CR Jr (1998) The effect of the repeated administration of the compound 3,4-methylenedioxymethamphetamine on the response of rats to the 5-HT2A, C receptor agonist (+/-)-1-(2,5-dimethoxy-4iodophenyl)-2-aminopropane (DOI). Neuropsychobiology 37:36-40.

Green AR, Cross AJ, Goodwin GM (1995) Review of the pharmacology and clinical pharmacology of 3,4-methylenedioxymethamphetamine (MDMA or "Ecstasy"). Psychopharmacology 119:247-260.

Gresch PJ, Walker PD (1999) Serotonin-2 receptor stimulation normalizes striatal preprotachykinin messenger RNA in an animal model of Parkinson's disease. Neuroscience 93:831-841.

Iravani MM, Asari D, Patel J, Wieczorek WJ, Kruk ZL (2000) Direct effects of 3,4-methylenedioxymethamphetamine (MDMA) on serotonin or dopamine release and uptake in the caudate putamen, nucleus accumbens, substantia nigra pars reticulata, and the dorsal raphe nucleus slices. Synapse 36:275-285.

Iravani MM, Costa S, Jackson MJ, Tel BC, Cannizzaro C, Pearce RK, Jenner P
(2001) GDNF reverses priming for dyskinesia in MPTP-treated, L-DOPA-primed common marmosets. Eur J Neurosci 13:597-608.

Jenner P, Marsden CD (1986) The actions of 1-methyl-4-phenyl-1,2,3,6tetrahydropyridine in animals as a model of Parkinson's disease. J Neural Transm [Suppl] 20:11-39.

Jorgensen H, Riis M, Knigge U, Kjaer A, Warberg J (2003) Serotonin receptors involved in vasopressin and oxytocin secretion. J Neuroendocrinol 15:242-249.

Kannari K, Kurahashi K, Tomiyama M, Maeda T, Arai A, Baba M, Suda T, Matsunaga M (2002) Tandospirone citrate, a selective 5-HTla agonist, alleviates L-DOPA-induced dyskinesia in patients with Parkinson's disease. No To Shinkei 54:133-137.

Lyon RA, Glennon RA, Titeler M (1986) 3,4-Methylenedioxymethamphetamine (MDMA): stereoselective interactions at brain 5-HT1 and 5-HT2 receptors. Psychopharmacology 88:525-526.

Maratos EC, Jackson MJ, Pearce RK, Jenner P (2001) Antiparkinsonian activity and dyskinesia risk of ropinirole and L-DOPA combination therapy in drug naive MPTP-lesioned common marmosets (Callithrix jacchus). Mov Disord 16:631-641.

Nicholson SL, Brotchie JM (2002) 5-Hydroxytryptamine (5-HT, serotonin) and Parkinson's disease: opportunities for novel therapeutics to reduce the problems of levodopa therapy. Eur J Neurol 9[Suppl 3]:1-6.

Oh JD, Bibbiani F, Chase TN (2002) Quetiapine attenuates levodopainduced motor complications in rodent and primate parkinsonian models. Exp Neurol 177:557-564.

Paulus MP, Geyer MA (1992) The effects Of MDMA and other methylenedioxy-substituted phenylalkylamines on the structure of rat locomotor-activity. Neuropsychopharmacology 7:15-31.

Pearce RK, Jackson M, Smith L, Jenner P, Marsden CD (1995) Chronic L-DOPA administration induces dyskinesias in the 1-methyl-4-phenyl1,2,3,6-tetrahydropyridine-treated common marmoset (Callithrix jacchus). Mov Disord 10:731-740.

Radja F, Descarries L, Dewar KM, Reader TA (1993) Serotonin 5-HT1 and 5 -HT2 receptors in adult rat brain after neonatal destruction of nigrostriatal dopamine neurons: a quantitative autoradiographic study. Brain Res 606:273-285.

Reneman L, Endert E, de Bruin K, Lavalaye J, Feenstra MG, de WolffFA, Booij J (2002) The acute and chronic effects of MDMA ("ecstasy") on cortical 5-HT2A receptors in rat and human brain. Neuropsychopharmacology 26:387-396.

Rempel NL, Callaway CW, Geyer MA (1993) Serotonin1B receptor activation mimics behavioral effects of presynaptic serotonin release. Neuropsychopharmacology 8:201-211.

Sarhan H, Cloez-Tayarani I, Massot O, Fillion MP, Fillion G (1999) 5-HT1B receptors modulate release of $\left[{ }^{3} \mathrm{H}\right]$ dopamine from rat striatal synaptosomes. Naunyn Schmiedebergs Arch Pharmacol 359:40-47.

Sarhan H, Grimaldi B, Hen R, Fillion G (2000) 5-HT1B receptors modulate release of $\left[{ }^{3} \mathrm{H}\right]$ dopamine from rat striatal synaptosomes: further evidence using 5-HT moduline, polyclonal 5-HT1B receptor antibodies and 5 -HT1B receptor knock-out mice. Naunyn Schmiedebergs Arch Pharmacol 361:12-18.

Scraggs PR, Ridley RM (1978) Behavioural effects of amphetamine in a small primate: relative potencies of the D- and L-isomers. Psychopharmacology (Berl) 59:243-245.

Smith LA, Tel BC, Jackson MJ, Hansard MJ, Braceras R, Bonhomme C, Chezaubernard C, Del Signore S, Rose S, Jenner P (2002) Repeated administration of piribedil induces less dyskinesia than L-dopa in MPTPtreated common marmosets: a behavioural and biochemical investigation. Mov Disord 17:887-901.

Sprague JE, Everman SL, Nichols DE (1998) An integrated hypothesis for the serotonergic axonal loss induced by 3,4-methylenedioxymethamphetamine. Neurotoxicology 19:427-441.

Treseder SA, Smith LA, Jenner P (2000) Endogenous dopaminergic tone and dopamine agonist action. Mov Disord 15:804-812. 